\title{
The Journal of Multidisciplinary Research (TJMDR)
}

\author{
Economic evaluation of management information system (mis) in health care management \\ Anamika Choudhary \\ Associate Professor,Department of Economics, DSMNR University, Lucknow, India
}

\begin{abstract}
Article History: Received: 05 June, 2021 Revised: 22 July, 2021 Accepted: 02 August,2021

There is undoubtedly a need to efficiently allocate the scarce resources related to health care so that the optimum utilization for the benefit of the society at large can be determined. In this process, the health management system plays an important role. A wellmanaged data becomes a significant source in making the organization efficient. Economics thus provides health sector a new paradigm- Health Economics. A branch of economics developed as Health economics deals mainly with how the scarce health care resources need to be allocated so as to bring the maximization of the health of the community. For such a decision making, an analytical tool is required which could involve both the cost and the benefit side. Economic evaluation serves such an analytical tool. The present paper focuses on the economic evaluation of the Management Information system (MIS) in Health care Management. MIS calls for such a strategy to effectively organize relevant information in the health care and manage the limited resources with optimization and is therefore considered superior to the traditional paper based system.
\end{abstract}

Keywords: Management Information system, optimization, efficiency, economic evaluation, health care management, decision making.

\author{
Corresponding Author \\ Anamika Choudhary \\ Email: choudhary.anamika15@gmail.com
}

How to Cite

Choudhary, A. (2021). The Economic evaluation of management information system (MIS) in health care management . The Journal of Multidisciplinary Research, 1(1), 17-22. https://doi.org/10.37022/tjmdr.v1i1.219

This article is licensed under a Creative Commons Attribution-Non Commercial 4.0 International license. Copyright (C) 2021 Author(s) retain the copyright of this article.

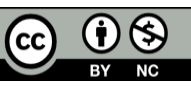

In developed countries, the micro-economists attempt to apply the tools of economic theory to the allocation of resources in the health sector, which brings health economics under the realm of microeconomics while in developing countries such as India, the development of health technology assessment faces various impediments like lack of professional expertise, system of reporting not being much effective, meager budget allocation etc. Data thus has to be well managed to efficiently run the organization. In the light of this understanding, the present paper aims to achieve the following objectives:

\section{Objectives of the study}

- To study the growth of the health care sector in India since 2010 .

- To analyze the trend of the public health expenditure as a percentage of Gross Domestic Product (GDP).
- To examine the significance of health economics in effectively allocating scarce resources to improve health care services.

- To examine the need for economic evaluation of Management Information System (MIS) in Health Care Decision Making.

- To study the role and impact of MIS in the working operations of health care management

- To find out the challenges faced in the efficient decision making.

\section{Methodology}

The present descriptive study focuses upon the economic evaluation of Management Information System (MIS) in the health care management. Different research papers have been reviewed and varied literatures have been surveyed to analyze the requisite information regarding MIS. Data have been collected from secondary sources for studying the growth of 
public expenditure. Diagrammatic presentations have been incorporated to study the components of MIS. Bar graphs have been used to present and analyze the data accordingly. The entire paper is divided into three sections.

Section I deals with the introduction of Indian Health care sector and the growth of public health expenditure. Section II focuses on the need of economic evaluation of Management Information System in the health care management system. Section III analyzes the role and impact of Management Information System, its different strategy and applications along with the challenges that it faces in the decision making process of the health care system.

\section{Section I}

\section{Introduction}

On to the journey of Sustainable Development Goals (SDG), which started in September 2015, the world is consistently making progress in many fronts of human development. There has been economic growth and with the increased efficacy of the public taxation, public revenue has been on the rise, which is effectively contributing to increase in both public and private spending on health. Conclusively, the health sector seems to grow faster than the growth rate of the economy. Being one of the fastest growing industries, the Indian Health care sector is expected to grow at a compound annual growth rate of $17 \%$ during the period 2011 to 2020 to touch US $\$ 280$ billion [8]. By 2020, Indian Health care sector was expected that it would be with the top three health care markets when measured in terms of incremental growth. Total spending on public health was 5 percent of GDP in 2013 and was expected to continue the same for the next 5 years.

In developing countries, like India, people have started becoming more aware and expect an efficient health care with better standards. Their access to required health services has seen an improvement in all regions of the world and even for all income groups. People are now better informed about their health criteria and the options of treatments available to them. Though they would like to owe the responsibility of their health but they would never like to pay more than they already pay for their health care. The budget estimates for fiscal year 2018 estimated that about 1.3 percent of the nation's GDP was directed to public health expenditure (table o1). This percent was 1.17 percent in the fiscal year 2017. Thus only a slight increase was observed.

Table 01. Public health expenditure as a share of India's GDP from 2010 to 2018

\begin{tabular}{|c|c|}
\hline Financial Year & Share of GDP (in percent) \\
\hline FY 2010 & 1.12 \\
\hline FY 2011 & 1.07 \\
\hline FY 2012 & 1.1 \\
\hline FY 2013 & 1.09 \\
\hline FY 2014 & 1 \\
\hline FY 2015 & 0.98 \\
\hline FY 2016 & 1.02 \\
\hline FY 2017 & 1.17 \\
\hline FY 2018 & 1.28 \\
\hline
\end{tabular}

Source : Statista 2021, Published by Statista Research Department, Apr 23, 2021

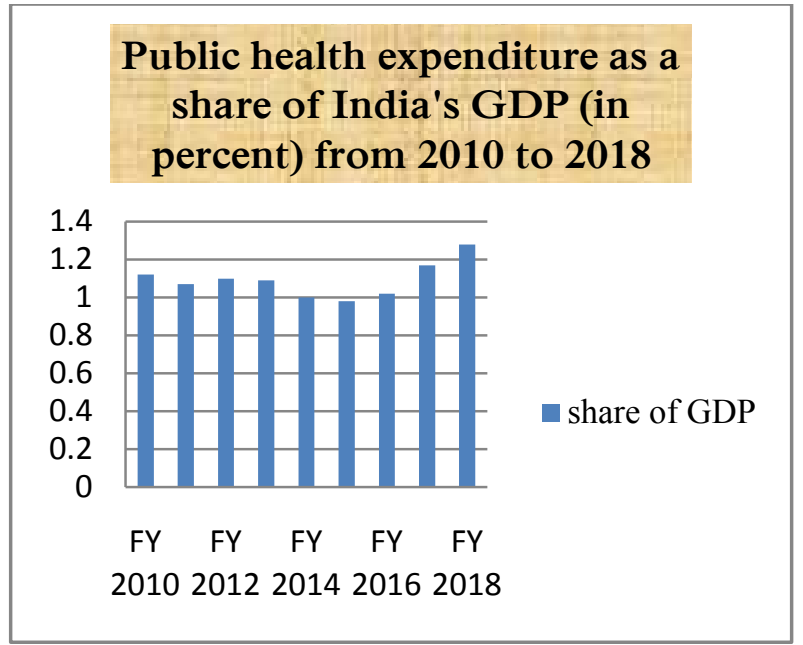

Fig 01: Public Health expenditure as a share of India's GDP from 2010-2018

Health Expenditure: In 2013, the total health care spending which was estimated to be $\$ 96.3$ billion increased only to $\$ 195.7$ billion, a rise of an annual rate of more than 12 percent [2].This rapid growth rate surely reflects high inflation, but it incorporates both increasing public and private expenditures on health. According to the World health Organization 2019 report [9], "Health spending is transitioning globally, with a rapid increase in domestic spending, both out-of-pocket and publicly funded. The health sector continues to expand faster than the economy. Between 2000 and 2017, global health spending in real terms grew by $3.9 \%$ a year while the economy grew $3.0 \%$ a year."

The micro-economists aim to allocate the scarce resources in every sector, herein to the health sector by applying the tools of economic theory. Thus, health sector becomes one of the subjects of study in micro-economics. There is undoubtedly a need to efficiently allocate the scarce resources related to health care so that the optimum utilization for the benefit of the society at large can be determined. In this process, the health management system based on MIS plays an important role. A well-managed data becomes a significant source in making the organization efficient. Economics thus provides health sector a new paradigm- Health Economics. Health economics is the branch of economics concerned with how scarce health care resources are allocated to maximize the health of the community. It examines as well as evaluates issues that deal with the efficiency of the resources available for health care, their effectiveness and how much value do they hold.

A health care intervention aims to improve health by making the preventive measures available, by making the best possible treatments and related medical procedures. With the discrepancy in health services provision across the country, and with health care expenditure on the rise, a need for effective utilization of health care resources emanates. Economics is concerned with the optimum allocation of the scarce resources, may it be any sector, health economics herein particularly deals with the allocation of such resources that aims to improve health. 


\section{Section II}

\section{Need of Economic Evaluation}

Utility in economics deals with the satisfaction of human wants through the consumption of goods and services. Health care can also be regarded as a good, though not a final good but an intermediate one as it is a means to bring an end result by improving health. In order that the scarce resources are efficiently allocated on a priority basis, an analytical tool is required which can evaluate the cost and benefit of a project in its implementation and compare it with other projects to find out which would be more cost effective. This would assist in the decision making process. Economic evaluation is such an analytical tool which helps in decision making. "The biggest challenge in this evolutionary method is lack of understanding of methods in current use by all those involved in the provision and purchasing of health care [1]." In publicly funded health care systems, because of limited resources, the provisions of the interventions available are restricted for all those who need it. Though the traditional classification of economic evaluation consists of four parts as mentioned below:

Traditional classification of economic evaluation

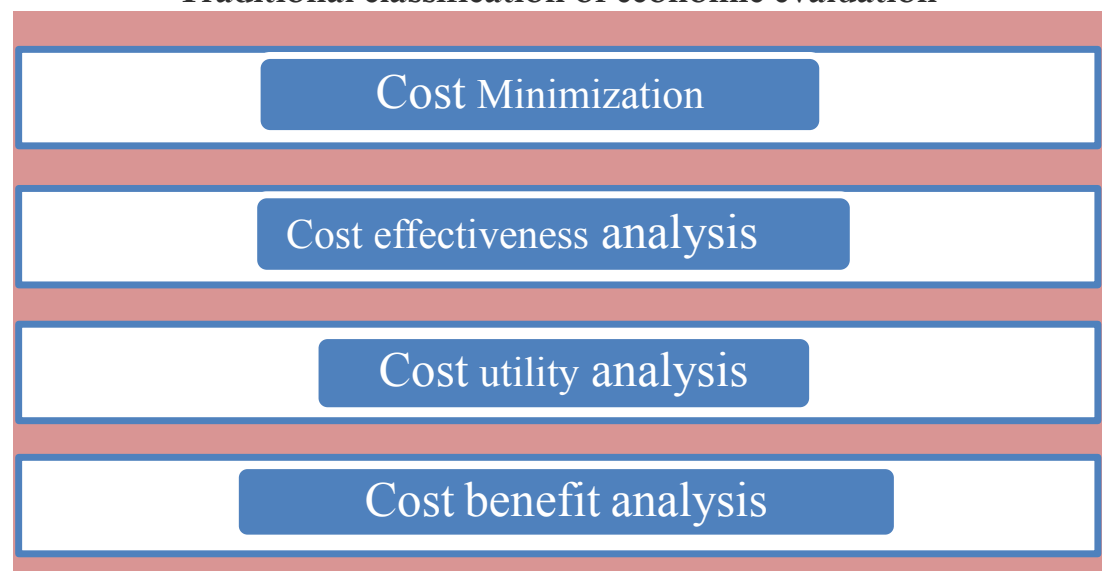

In India, economic evaluations have generally suffered from uncertainty as the guidelines adopted were subject to hesitation. For appropriate decision making, economic evaluation is must, may it be any country indeed.

\section{Economic Evaluation is used in Health Care Decision Making}

When there is a choice in the decision making process, funding one intervention means that other interventions cannot be funded. Morris, Devlin and Parkin (2012) [4] state different reasons of using economic evaluation in health care decision making. They consider that benefits from health care spending must be maximized and regional variations need to be overcome. They consider that economic evaluation would help to control costs and demand can also be managed. It also boosts the bargaining power of the suppliers who provide the health care benefits. Further, as stated by Devlin, economic evaluations come into play in various types of decisions regarding drug treatments, health care programs, making investment in innovative technology or research.

When the criteria of efficacy of the program, effectiveness of its working and making it acceptable and also the availability to those who need it are fulfilled, economic evaluation become truly useful in health care management. Just as clinical trials for any drug becomes the most important criteria to establish its efficacy and effectiveness.

The pharmacoeconomic research in India can be improved when guidelines for it are formulated by the government. Beside this, economic evaluations when done before any health policy decision making also helps to improve it. It would not be wrong to say that India has highly skilled and quality trained medical professionals but at the same time, the patient pool is also large enough. Not only in the medical field but in the field of information technology, there are so many skilled professionals who are the human capital of the nation. They can work together to manage data and records maintaining its reliability at the same time.

\section{Management Information System (MIS)}

The efficacy and effectiveness in the health care system can be built efficiently when all such health related relevant information are managed in a systematic manner. This calls for computerization. Management Information System (MIS) thus play a crucial role in processing the available data because information is the core necessity for achieving the competitive advantage [6].

Before understanding the role of MIS in the economic evaluation of Health care management, it is essential to know its meaning and structure. In MIS, 'Management' refers to the function of doing the given work by the right person at the right time that is meant for the given job. The data when collected and organized becomes 'information' and this information plays a crucial role in the making of decision. The last term 'system' is a set of elements that lays down the framework of transforming an unorganized data into an organized one.

\section{Components of MIS and their relationship}

The economic evaluation of health care management through MIS requires to understand its components which can work together to achieve the goal of optimum allocation of resources in the health care. The five major components are qualified professionals who use the information system to keep a record of each day transaction, the business procedures which act as a guide for the users to initiate an efficient working. The third component is the data i.e. the day to day transaction, the fourth being the hardware and the fifth is the software. 


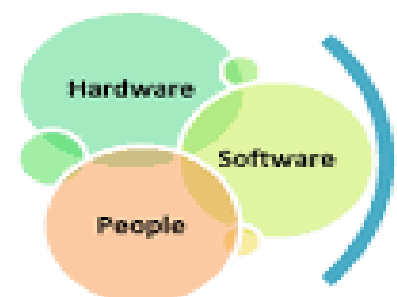

Components

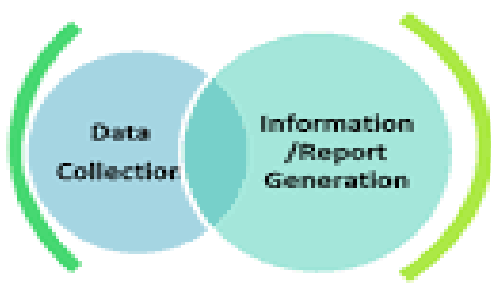

Process

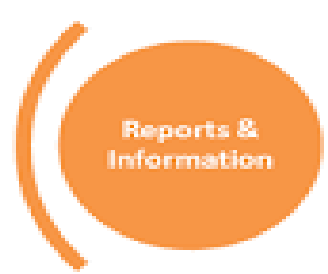

MIS

Source: researchgate.net

The circular flow diagram below explains how MIS helps to provide information in accuracy to the entire management levels thereby helping in the decision making process.

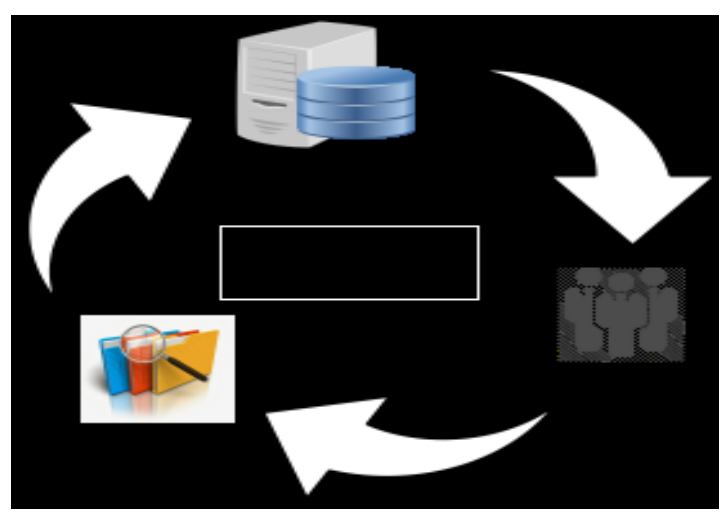

Source: Slideshare.com

The primary advantage of MIS is that it can forecast the further business processing on the basis of the historic data. The information restored in the form of reports, images, videos or audio file provides a facilitation of comparing when the given information is represented in the form of charts, tables, etc. Thus MIS aims to captures the data, process it, store the information, retrieve the information and then disseminate it. This readily helps in the economic evaluation of the health care management without wastage of resources and helps to process the decision making effectively.

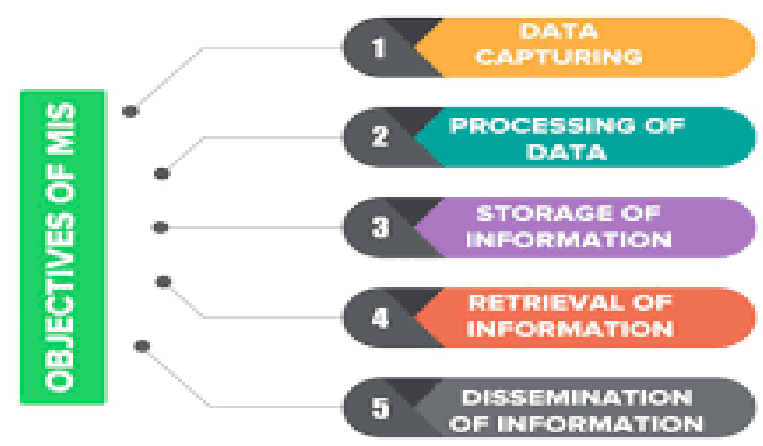

\section{Section III}

\section{Role of Management Information System}

Preventive measures, adequate treatment and apt medical procedures at the right time are the aim of any health care intervention. Herein lays the role of Management Information system. When the organization becomes highly complex, only correct information at the needed time can help in decision making process. This system is technically better than the traditional paper based system (TPBS). Being highly effective and facilitating end user satisfaction, MIS can be considered to be more useful in economic evaluation of health care management. 'Accuracy of data', 'content of the system' and the 'timely availability' [8] features provide an edge upon the traditional paper based system (Kanchan Mukherjee, et.al). The health records should be reliable so as to cater to the needs of the stakeholders. No doubt the MIS is computerized based and involves relatively more cost in terms of hardware, software, professionals, electricity, stationary etc. so it goes as MIS is both high cost and highly effective which minimizes the errors and stores a vast amount of health records without any damage.

When the system is effective, the records collected are also reliable. It helps the patient to get his procedure redressed without taking longer time. The advantage of a TPBS system was that any corrections like rewriting or overwriting was manageable and the end user was quite familiar with this system but as far as accessing the information is concerned, handling the data and its storage is concerned, MIS ought to be superior. Writing down work excessively got reduced and even likeliness of the work being postponed seems out of question. Though TPBS can be considered user friendly in the first instance but in the long run, computerization of health data record is worth to be accounted for.

"The information is the blood and MIS is the heart." [3] Each functional department of the hospital can function effectively and efficiently when reports are generated and management takes note of these records to make advance plans. MIS also helps to find out the solution of any such mistake that is made by the heath care management. Each year performance is analyzed effectively which helps in the organizational development and growth. The MIS assists the management in planning, managing, target setting and regulating the hospital functions.

Strategy of MIS towards increasing and optimizing Health Resources

By using computers in health care system, managing records, comparing records, creating historic data base, dissemination of information becomes easily accessible, enhancing the quality and thereby changing the fundamental dynamics of health care economics. Any kind of health related information, may it be clinical information, insurance 
information, referral information, changing pattern of diseases, emergence of new health financing methods, new health insurance schemes, what we miss is a careful planning or a method especially for achieving a meaningful end. MIS calls for such a strategy to effectively organize relevant information and manage the limited resources with optimization.

When it comes to the health care system, MIS helps to improve the accessibility, and ensures equity in the provision of health services. Though the capital cost may be high in terms of hardware, software, skilled and qualified professionals and electricity charges etc., reduction of wastage compliments for the increasing coat and make it more cost efficient. The very significant achievement of MIS can be looked in the quality of health care which drastically improves with the application of this system.

MIS is widely used in the Health care system as it offers not only resource and utilization management but also patient care management and quality management. The personal health information of the patient and the information of his treatment along with the drug details when provided at the right time without any time lag is a reflection of management efficiency. This will bring a tremendous improvement in the health care of the patient concerned and also in providing referrals in other cases.

As economics is concerned with the allocation of scarce resources for its optimum utilization, management information system would enable the resources related to health industry to bring in efficacy, efficiency and better accessibility to the relevant information, thereby enhancing the productivity of the health care system.

\section{Importance of MIS}

In today's world, where complexities in each organization is a common thing, the health care organization does require a well-structured method of collecting and disseminating information in a reliable and timely manner and only a planned, and properly designed MIS can help to bring speedy decisions. On the contrary, if the MIS is not properly structured or poorly maintained, it is going to cost the organization and any inaccurate or obsolete information may prove fatal. Economies of scale that are enjoyed by the bigger hospitals can be enjoyed by the small ones too if they follow MIS. This would help to economize on their resources providing efficiency to the healthcare management and thus getting a competitive edge over other hospitals.

Use of computers instead of traditional paper based system enhances managerial efficiency. With a variety of tools of management, they try to exercise experimentation and try modeling by using the tools and techniques which are difficult to be used manually. Overall, the evaluation of the health care management becomes more efficient and effective when the allocations of the resources which are scarce are managed through MIS.

As the management information system works on a basic computer system by making database, the work of the clerical staff is reduced. It relieves manpower for other related work which requires more manual input. The human mind can then be put to other better work. The overhead expenses are minimized and simultaneously an information based working culture is established in the organization.

The delivery of quality services in the hospital organization in a cost effective manner is a boon to the patients as their out of pocket expenditure squeeze their pockets. Providing sound decisions by the decision makers in the organization is enabled by MIS. Their profits are enhanced with rise in efficiency, effectiveness and efficacy.

\section{Challenges in decision making}

First, in this age of globalization, decision making should not only be apt but also quick as the competition is not just local level but also globally. If the managers are not able to take quick decisions, it would not be possible for the particular health organization to survive in the face of its competitors. This again gives a sound reason for the establishment of such a system.

Second, as the information regarding the patients, or the drug or the treatment etc. is incessantly increasing day by day, a manager is assigned to process a huge amount of data in the minimum time duration, failing which the decisions taken by him may cost heavily to the company. For that matter, the managers must be equipped with some tool to smoothen their process. Else they may face severe challenges in the decision making.

\section{Findings and Conclusion}

Management Information system (MIS) is considered to be the main axis of any health organization and is considered to be highly significant in the today's age of globalization and liberalization. Such a system is required to cater information to the decision makers so that the organization can achieve its goals. Any kind of health related information, may it be clinical information, or that of insurance or referral or the case may be that of changing pattern of diseases, only and only a careful planning or a well strategic method can produce a meaningful end. It can also be concluded that in comparison to traditional paper based system, MIS is highly effective though the capital cost may rise but the efficacy of the system and the reliability of the data makes MIS superior to the traditional paper based one. Also, that the end user satisfaction is found to be increasingly better in MIS as there is no loss or damage to the health records. MIS calls for such a strategy to effectively organize relevant information and manage the limited resources with optimization.

\section{References}

1. Cameron.A, M Ewen Dip, Ross-Degnan D, et al. (2009): "Medicine prices, availability, and affordability in 36 developing and middle-income countries: a secondary analysis", The Lancet, 373 (9659), pp. 191-193,https://doi.org/10.1016/S01406736(08)61762-6

2. Dang Amit, Nishkarsh Likhar, Utkarsh Alok (2016): Importance of Economic Evaluation in Health Care: An Indian Perspective, Value in Health regional issues, 9C, Elsevier publications, pp. 78-83, journal homepage: www.elsevier.com/locate/vhri

3. Das Nageshwar (2018): Role of the Management Information System (MIS) 
4. https://www.healthknowledge.org.uk/public-healthtextbook/medical-sociology-policy-economics/4dhealth-economics/health-care-decision-making

5. Rascati KL. (2009): Essentials of Pharmacoeconomics. Chapter 13: International perspective. Philadelphia, PA: Lippincott Williams and Wilkins.

6. Tripathi K P (2010) MIS is an Effective Tool to Decision Making International Journal of Computer Applications 7(11) DOI: 10.5120/1290-1757

7. Kanchan Mukherjee Periasamy Karuppiah Amarnath Babu (2014) Economic evaluation of hospital management information systems in Tamil Nadu, India International Journal of Medicine and Public Health, Vol 4,Issue 3. ,https://www.ijmedph.org/sites/default/files/IntJMed PublicHealth_2014_4_3_269_137715.pdf

8. https://www.who.int/health_financing/documents/he alth-expenditure-report-2019.pdf.

9. https://www.statista.com/statistics/953163/indiapublic-expenditure-on-health-as-a-share-of-gdp. 